\title{
Mitigating shadow economy through dual banking sector development in Malaysia
}

\begin{abstract}
Theory argues that as long as the shadow economy is of sufficient size, the leakage or loss of tax revenue through tax evasion will also be substantial. In this chapter, we provide new estimates of the size of the shadow economy in Malaysia for the period 1971-2013. Further, we relate the shadow economy to its determinants as measured by the misery index. This chapter reveals that the relationship between the shadow economy and financial development in Malaysia exhibits an inverted U-shaped curve. The chapter concludes that the Malaysian government should embark on programs that can reduce the size of the shadow economy, relying on its dual banking system of Islamic and conventional banks.
\end{abstract}

Keyword: Shadow economy; Islamic banking; Malaysia 